\title{
0 espaço local e 0 estudo dos ganhos democráticos via participação política online
}

\author{
Local space and the study of democratic rewards through e-participation
}

\author{
Rodrigo Carreiro \\ Mestre em Comunicação e Cultura Contemporânea, \\ Grupo de Pesquisa Comunicação, Internet e \\ Democracia, Pesquisador do Centro de Estudos \\ Avançados em Governo Eletrônico e Democracia Digital, \\ Universidade Federal da Bahia - UFBA, \\ e-mail: rodrigocarreiro@gmail.com
}

RESUMO $\mathrm{O}$ artigo tem como objetivo estudar a participação online da perspectiva da sociedade civil, abordando como os processos participativos na internet podem gerar ganhos democráticos para os envolvidos. O trabalho segue a linha teórica que compreende as conversações civis e trocas comunicativas cotidianas como importantes aspectos para entender o envolvimento político do cidadão nas questões que o cercam. Levando em consideração essas questões, o artigo sistematiza quatro categorias de ganhos a serem analisadas: informação, ação educativa, comunidade e monitoramento do poder. Elas serão discutidas à luz do campo teórico e da exemplificação de casos prospectados. Portanto, o trabalho contribui para entender a efetividade da participação na ponta final do processo, além de buscar subsídios para estabelecer ganhos efetivos para o cidadão que participa.

PalaVras-ChaVe Democracia digital; Participação; Ganhos democráticos; Espaço local.

ABSTRACT The article aims to analyze the e-participation through the civil society perspective, studying how the online participative processes can generate democratic gains for those who are involved. The work is developed on the theoretical framework of civic conversations and communicative exchanges through everyday life as important aspects to understand the citizens' political involvement on the issues around them. Taking these into account, the article systematizes four categories of democratic gains (information, educative action, community and monitoring the power) that will be analyzed in light of the presented theoretical framework and examples gathered on the internet. Accordingly, this study is a contribution to understand the effectiveness of participation at its end, and also offers subsidies for the study of democratic gains for those who participate.

KEYWORDS E-democracy; Political participation; Democratic gains; Local space. 


\section{Introdução}

A compreensão do papel das tecnologias digitais na comunicação política contemporânea envolve questões que vão desde a análise e implantação de modelos de participação e deliberação por parte de governos, até o estudo de novas alternativas para reivindicações civis na esfera pública. A literatura tem se preocupado bastante com o desenho das ferramentas e outras questões normativas referentes ao modo como o input participativo é criado, gerenciado e até posto em prática. No entanto, há poucos estudos que se concentram em entender quais os ganhos democráticos gerados para os envolvidos. Este tipo de investigação (1) estabelece a efetividade do processo na ponta final da participação; (2) analisa o processo à luz da sua importância para a saúde do sistema democrático.

Para elucidar algumas dessas questões, o presente artigo desenvolve um estudo analítico que visa estabelecer e investigar ganhos democráticos que são gerados para o cidadão que se envolve em processos participativos online. Mais precisamente, foca sua atenção em ferramentas de participação de âmbito local. O corpo analítico se dá dessa forma pelo fato de que há poucos trabalhos na área e, portanto, há uma necessidade de sistematização de tais ferramentas, além de que esses sites oferecem subsídios mais direcionados para o propósito do artigo. Estudar participação e espaço local atualmente sugere a compreensão de que o envolvimento político do cidadão se projeta no âmbito das relações sociais cotidianas, trocas informativas e outros processos de comunicação menos formais, em que cidadãos articulam idéias e discutem problemas relacionados ao campo local, de modo que a internet ocupa espaço destacado.

Levando em consideração essas questões - e que serão desenvolvidas a seguir - o artigo sistematiza quatro categorias de ganhos a serem analisadas: informação, ação educativa, comunidade e monitoramento do poder. Elas serão discutidas à luz do campo teórico e da exemplificação de casos prospectados.

\section{Representação, Participação e os Meios Digitais}

A rigor, o diagnóstico que hoje se faz da democracia não é de uma crise do modelo em si, mas sim do seu sistema representativo calcado em alguns valores pouco aprimorados (Gomes, 2008). Para que se coloque em discussão questões práticas advindas das alternativas democráticas - isto é, práticas e apropriações sociais da internet que visam, em algum modo, a melhoria democrática via participação ou deliberação pública -, é necessário que se entenda alguns aspectos que apontam para o desgaste do atual sistema representativo do ponto de vista da participação.

Primeiro, os Governos tomam, a partir do período pós-segunda guerra, mais poder para si no quesito economia, criando novas estruturas administrativas e acumulando mais controle sobre o mercado. Advém daí, por exemplo, a necessidade de uma administração pública mais intervencionista, salvando até bancos privados da bancarrota (Held, 2006) - pois isso, obviamente, acarretaria em problemas conjunturais para o Estado. Segundo, para manter a máquina funcionando, são necessários novos cargos e novas linhas de atuação administrativa, o que acarreta no aumento da complexidade das estruturas do Estado. Terceiro, crescem as despesas do Estado em consequiência de mais intervenção e de custos para manter o funcionalismo público. "Esse desenvolvimento, então, estimula ainda mais demandas para o Estado, como por exemplo, de participação e consulta sobre decisões [...]" (Held, 2006: 196).

A avaliação mais direta desse quadro pode ser resumida em alguns aspectos: sentimento geral de que o governo é corrupto, intocável e distante (Coleman e Blumler, 2009); mesmo que haja possibilidade, mínima que seja, de contato com a esfera política, o entendimento geral é de que a opinião não será levada a sério; noção de que os representantes não representam interesses públicos, e sim interesses próprios; baixa taxa de participação em eleições em países onde o voto não é obrigatório; com baixa participação geral, a classe política tende a estar mais livre para atuar em seus próprios termos e regras (Pateman, 1992); sensação geral de pouca transparência e baixa responsividade do Estado (Bucy e Gregson, 2001); o Estado não consegue prover seus cidadãos de suas necessidades, principalmente das classes menos favorecidas (Teixeira, 2002); dentre outros.

O sujeito atingido por esses problemas seria, portanto, a sociedade civil, o ser público e a cidadania (Gomes, 2008). Assim, verifica-se que há, de um lado, autores que afirmam que os indivíduos estão cobrando mais e assumindo mais as rédeas de seu destino político (Teixeira, 2002; Coleman, 2009; Coleman e Blumler, 2009) e, do outro, autores que se escoram em estudos empíricos (mais notadamente de 
raiz americana ${ }^{1}$ ) para sentenciar a apatia dos cidadãos perante a política e suas implicações (Ward e Gibson, 2009).

A perspectiva participativa, como alternativa democrática mais explorada pelo menos nos últimos 20 anos, forma-se nesse ínterim de desgastes estruturais do Estado. $\mathrm{O}$ fator novidade, que contribuiu para essa exploração, é a internet, que se mostrou a nova alternativa aplicação prática de pressupostos teóricos que vem sendo discutidos desde pensadores tidos como clássicos (Rousseau, 2006; Mill, 2009), até autores mais recentes, a exemplo de Barber (1984).

A interface internet e democracia oferece um cardápio vasto de características e possibilidades de interação (Gomes, 2005). Tais aspectos permitem que o cidadão - pelo menos de forma potencial - as transformem em oportunidade reais de envolvimento e influência política. Com esse objetivo, o processo envolve: cidadãos (e/ou suas diferentes formas de organização), políticos e instituições governamentais; na extensão e transformação da participação em processos sociais democráticos e consultivos, mediados pelas tecnologias de informação e comunicação (Saebo, Rose e Molka-Danielsen, 2010).

A participação online deve ser compreendida dentro dos estudos em democracia digital ou e-democracia (e-democracy). A assertiva um tanto quanto óbvia é necessária, pois esclarece diversas questões e problemas acima apresentados. Certamente, pode-se procurar definições em diferentes autores que dão, dentro de suas conceituações, pesos diferentes a questões como transparência, accountability e governo eletrônico. No entanto, verifica-se que há certa tendência em valorizar participação, isto é, em assumir que democracia digital busca algum tipo de contato maior entre esfera civil e classe política/ decisões políticas.

Entendo por democracia digital qualquer forma de emprego de dispositivos (computadores, celulares, smart phones, palmtops, ipads...), aplicativos (programas) e ferramentas (fóruns, sites, redes sociais, medias sociais...) de tecnologias digitais de comunicação para suplementar, reforçar ou corrigir aspectos e práticas políticas e sociais do Estado e dos cidadãos, em benefício do teor democrático da comunidade política [...] (Gomes, 2011: 28).

\footnotetext{
Obtém especial destaque nessa questão a obra de Robert Putman, Bowling Alone (2000)
}

A definição acima² resume claramente os diversos propósitos da democracia digital, mas uma avaliação mais profunda consegue identificar que a participação política ganha especial atenção, tanto teoricamente quanto em termos práticos. Coleman e Norris (2005) seguem por caminho parecido, enfatizando que se a avaliação geral é de que as democracias modernas carecem de participação cidadã como um todo, então os recursos das tecnologias da informação e comunicação são essenciais para suprir essa necessidade. Chadwick (2006) é outro autor que dá importância à participação via dispositivos digitais, pois acredita que é preciso que os cidadãos utilizem as armas que são convenientes e disponíveis em seu contexto social. Neste caso, há uma preocupação com aqueles cidadãos que normalmente não dispõem de oportunidades participativas, mas que com a internet novos canais se abrem para eles (Schlosberg e Dryzek, 2002), sendo esse aspecto o mais exaltado da democracia digital. Na visão de Marques (2008), há uma diferença marcante entre iniciativas de e-dem do Estado e da sociedade civil. Enquanto esta se preocupa em diminuir o hiato participativo, o outro também precisa estar atento à "[...] diminuição da burocracia e efetividade dos serviços do estado [...]" (Marques, 2008: 269).

A circulação de informação política pública, assim como os demais temas citados acima, depende, em alguma medida, de aspectos administrativos (Coleman e Norris, 2005). A questão é: uma vez bem desenhado um projeto de democracia digital, com participação ativa de cidadãos e até membros políticos, como tornar tudo isso tangível do ponto de vista da geração de resultados?

\section{Uma Compreensão Prévia Necessária: 0 Paradigma da Política Local e Suas Três Dimensões de Estudo}

Alguns projetos governamentais de participação online local têm procurado responder a questão posta no último parágrafo acoplando ferramentas em planos maiores e elaborados no âmbito administrativo. Nos EUA, por exemplo, há um documento (Open Government $^{3}$ ) que estabelece padrões de governo

\footnotetext{
Em texto anterior, o mesmo autor se preocupou em enfatizar com mais clareza a questão da aplicabilidade prática dessas iniciativas de democracia digital. Isto é, Wilson Gomes (2005: 3) estabelece que o desenho dessas aplicações deve se acoplar às estruturas do Estado para que seus resultados sejam realmente efetivos, tendo em vista que iniciativas podem ser alternativas às "[...] instituições pré-existentes do Estado (padrão mínimo), outras vezes modificando ou re-configurando outras instituições (padrão máximo) [...]"

${ }^{3}$ http://www.whitehouse.gov/Open
} 
eletrônico para todas as instâncias do poder nacional, que funciona como um guia de práticas digitais e um guarda-chuva de iniciativas de transparência e participação, incluindo instâncias locais. Já na Inglaterra, o governo desenvolveu um projeto de democracia local (UK Local Democracy Project), com o intuito de criar novos canais participativos por meio da internet. Nestes casos, busca-se aliar práticas comunicacionais do Estado com efetivação de resultados no âmbito da administração pública. Do contrário, essas iniciativas se perdem no meio da burocracia estatal e viram ou um problema para o governo - que não sabe efetivamente o que fazer com aquilo - ou não resultam em nada, já que são geridas por funcionários de médio escalão (Coleman e Norris, 2005).

Antes que se entre nessas questões mais diretamente, é preciso dar um passo lateral e entender sobre qual espaço local estamos tratando. Ou seja, estabelecer parâmetros de estudos que darão base para o entendimento dos ganhos democráticos que serão discutidos posteriormente. Assim, Frey (2003) explica que as mudanças estruturais dos Estados ocorridas nos últimos 25 anos, em escala global, afetaram profundamente a atuação dos governos locais. Diversos aspectos emergem a partir disso, como políticas de austeridade fiscal, desregulação e privatização, que vão impactar em ações que as municipalidades vão programar para seu próprio desenvolvimento. De forma genérica, como afirma Santos (2008), o espaço local é a base da ação reativa do cidadão.

Dessa forma, o espaço local também é locus de um paradigma o qual cidadãos, estados e organizações estão igualmente inseridos. Na medida em que a globalização se acentuou nos últimos 20 anos, as decisões políticas importantes foram sendo tomadas em ambientes globais, enquanto que o impacto desse processo é sentido, primordialmente, nos espaços locais em todo o mundo. Essa visão é defendida por diversos autores, como Dowbor (1998), Frey (2003), Santos (2008) e Gordon (2008), embora cada um com seu direcionamento particular. Essa questão envolve a estrutura política local em situações de claro entrave, pois é preciso que inúmeras questões superiores sejam resolvidas para que outras tantas sejam destravadas no espaço local ${ }^{4}$.

\footnotetext{
${ }^{4}$ Exemplos disso são financiamentos públicos condicionados a índices sociais mínimos. Isso, por sua vez, depende da permanência da cidade num plano nacional de financiamento. Determinada nação, como o Brasil, por exemplo, também depende da aprovação internacional, a partir de índice de desenvolvimento humano mínimo, para conseguir altos investimentos de entidades trans-nacionais, como o Fundo Monetário Internacional. Outro fator que influencia na questão são normas legais, como a Lei Kandir e a operacionalização de exportações (Egler, 2010) e o Estatuto da Cidade.
}

A alternativa participativa, no âmbito local, é defendida como uma reação direta e natural do cidadão para que questões de alcance cotidiano sejam resolvidas localmente (Frey, 2003; Dowbor, 1998). Na visão de Dowbor (1994), a questão é mais profunda e diz respeito a intervenções de colaboração já em nível local, isto é, antes de pensar em questões maiores de impacto global (meio ambiente, fome, pobreza etc.), é preciso que se pense em adversidades locais. É uma questão muito mais de interesse pontual do que de necessidade global (Dowbor, 1998). A diferença é que uma sociedade mais participativa e focada em seus interesses locais, torna-se uma fonte, inclusive, de sustentação do próprio poder estatal, pois esse passa a ser regido pelos interesses daqueles que o cercam.

Além disso, para o cidadão, esse tipo de prática participativa gera mais controle social sobre as decisões e condutas dos governos, contribuindo para a formação de uma nova cultural política local. A perspectiva deve se ater, portanto, em mudar o foco instrumental e paternalista de gestão local, rumando para diálogos mais contínuos com setores da sociedade. É um esforço endógeno, é verdade, mas que se traduz em práticas, iniciativas e esforços de dentro para fora, reforçando a capacidade dos cidadãos em pensar sobre assuntos que lhe cercam.

Para entender a relação entre participação e espaço local, faz-se necessário a definição de três parâmetros que darão subsídios para as discussões sobre ganhos democráticos para os cidadãos que participam politicamente em ambientes digitais. O primeiro deles é entender o espaço local como uma construção social compartilhada dos cidadãos. O compartilhamento pelos indivíduos é que vai dar o valor do local. Lefebvre (2001) empreende especial atenção ao "sentimento de pertencer" das pessoas, aos códigos em comum que cidadãos possuem e que, em menor ou maior grau, compartilham entre si, passando de geração para geração. Santos (2008), embora também não entenda essa diferenciação como dicotômica, caracteriza o local por dois gêneros de constituição. O primeiro é o limite territorial, físico e palpável. O outro é o "mundo" das normas e organização social que regulamenta o funcionamento do primeiro gênero.

Por isso, não há uma concepção final sobre determinado local, e sim uma ideia desenvolvida ao longo do tempo. Nesse caminho, percebe-se claramente a importância das trocas cotidianas para formação da ideia de determinado local, mas isso depende prioritariamente dos cidadãos. Se, como afirma Lefebvre, o cidadão tem o direito à cidade, ele também possui o dever com a cidade. Knudsen (2007), em um estudo em que também busca o autor francês para pensar a questão da construção sócio-política do 
espaço, argumenta que há a formação de um cidadão insurgente, que se molda a partir daquilo que ele é em relacionamento com o os outros cidadãos. As práticas cotidianas, portanto, “[...] são encontradas onde reivindicações para uma cidadania inclusiva e substancial são feitas e 'lutadas', a favor e contra [...]" (Knudsen, 2007: 9) ${ }^{5}$.

Avançando na questão, outro ponto a se considerar é a noção de política adotada no presente trabalho. Sem objetivar grandes discussões acerca do conceito em si, entende-se que, a partir do momento em que se pensa na valorização das relações cotidianas e no compartilhamento de códigos sociais fincados num local específico, a política passa a ter uma realização prática mais diluída e longe das amarras institucionais. Bobbio (1998) apresenta a ideia de política, a partir de sua gênese léxica, como referente "[...] à cidade e, conseqüentemente, o que é urbano, civil, público, e até mesmo sociável e social [...]" (Bobbio, 1998: 954). Obviamente que essa concepção remonta a tempos antigos, em que o domínio da cidade era o domínio da vida completa, pois não se tinha como referência uma ideia de estado total nem de mundo de extensão territorial vasta, como séculos seguintes mostrariam. Ainda assim, serve de bússola para indicar um parâmetro basilar o qual o presente trabalho se desenvolve, entendendo a política como "[...] forma de atividade ou práxis humana [...]" (Bobbio, 1998: 955) ${ }^{6}$.

O último ponto se refere à valorização da descentralização do poder local. Isso significa entender o panorama político local menos concentrado nas mãos do Estado, com forte participação da sociedade civil organizada. Em um trabalho que apresenta vasta revisão de literatura sobre o assunto, Silva, M. (2009) também mostra que o local é mais que o físico, mas vai além. Ela fala em relação de "redes estruturadas", isto é, em conjunto de pessoas ou instituições que defendem interesses identificáveis e específicos. Em diversos trabalhos, o pesquisador Ladislau Dowbor $(1994,1998)$ apresenta essa ideia, principalmente quando afirma que poder local envolve descentralização e desburocratização para uma verdadeira racionalização do espaço de vida do cidadão.

\footnotetext{
5 Tradução própria do original em inglês: "These practices are found where claims for an inclusive and substantial citizenship are made and fought, for and against [...]" (Knudsen, 2007: 9).

${ }^{6}$ Essa concepção não exclui a ideia nem a função do Estado, embora alguns estudos na área de política local tendam a diminuir o poder e necessidade do Estado na melhoria social da cidade. Mais à frente, quando o trabalho abordar os limites e perigos da perspectiva local de participação, essa questão será brevemente abordada.
}

Frey (2003), outro autor brasileiro que aborda a questão, segue na mesma linha, explicando que nenhum ator social consegue resolver problemas locais sem um intenso processo de interação com outros setores da sociedade - seja o cidadão ordinário ou a sociedade civil organizada. Por isso, o Estado não é único no processo de tomada de decisão.

\section{Os Ganhos Democráticos e o Cidadão Online}

Diante desse contexto e definida essas questões, é possível dizer que alguns autores chamam atenção para o caráter libertário da internet no quesito política local (Chadwick, 2006; Gordon 2008; Berger, 2009; Hampton, 2010), mesmo que isso não se transforme em decisões melhores ou que o Estado passe a ser mais poroso. Ora, se estamos tratando aqui (1) de uma concepção de política enraizada nas relações cotidianas, (2) na construção do valor de determinado local a partir das trocas comunicacionais e informacionais dos cidadãos, e (3) de certo nível de descentralização do poder, então podemos tentar buscar na internet um espaço que sirva como terreno para os processos participativos locais.

Por esse viés de análise, Gordon (2008) introduz a concepção de localidade em rede (network locality), que será visivelmente importante para o entendimento tanto dos casos apresentados na seção seguinte, quanto para entendermos de forma geral a posição defendida na dissertação. A premissa básica é de que as pessoas estão utilizando a internet para redefinir seus espaços, seja no âmbito da cultura, conhecimento ou entretenimento, seja no campo político (Gordon, 2008). A utilização das redes digitais altera a forma como as pessoas vêem seus locais; não uma alteração brusca e definitiva, mas um reordenamento de significados em constante mudança.

A pessoa continua existindo em casa, no quarteirão, na vizinhança, na cidade, mas as relações entre usuário e informação usadas para construir esses conceitos é que mudaram [...] (Gordon, 2008, online).

A partir disso, ao abordar o tema dos ganhos democráticos obtidos via participação, é preciso fazer uma ressalva fundamental. Não devemos entender a participação como um fim (Gomes, 2011). Mais precisamente, não podemos encarar o processo participativo como o objetivo único do Estado, pois é impensável que isso ocorra diante das questões sociais contemporâneas. Rousseau, como o arquiteto inicial do projeto de Estado Moderno, via a participação do povo nos negócios públicos como único modo de se 
alcançar a soberania popular, mas o principal ponto a ser levado em consideração sobre o pensador francês é a sua perspectiva contratualista - justamente o ponto adotado com mais clareza tanto por autores liberais, quanto por autores participativos. Isso significa entender o indivíduo como único e indivisível, com suas preferências pessoais inquestionáveis, mas participante ativo de um todo igual a ele e que só se legitima a partir disso.

Diante das questões sociais contemporâneas, é mais salutar imaginar a participação como uma parte do processo democrático, um meio para obtenção de ganhos ou recompensas cívicas que, a priori, dirige-se ao indivíduo em sua concepção única.

Rousseau (2006) e Pateman (1992) preferem estudar a participação a partir de suas funções, enquanto que, como vimos acima, Gomes (2011) fala em benefícios para os cidadãos. Outra perspectiva, a encontrada no trabalho de Bucy e Gregson (2001), vê a questão pelo viés das recompensas cívicas (civic rewards). Tentando se posicionar entre as funções, os benefícios e as recompensas, preferimos adotar o termo ganhos democráticos por alguns motivos. Inicialmente, como estamos adotando um contexto de democracia participativa, entende-se que a participação é um dos valores democráticos, a exemplo da transparência e da responsividade (Silva, S. P., 2009) e, por isso, pode gerar, assim como os outros valores, ganhos democráticos individuais. Estes não são ganhos únicos, nem muito menos mais importantes que os demais obtidos a partir de outros valores. Mas eles podem ser encarados diferentemente, pois para a presente pesquisa, eles são gerados para os cidadãos a partir de dois aspectos: das funções normativas e da mediação via meios digitais.

Quanto ao primeiro ponto, tais funções podem ser identificadas a partir de autores clássicos, como Rousseau (2006) e Mill (2009). Identifica-se, portanto, que a participação tem função educativa, na medida em que "ensina" os cidadãos a viverem respeitando as escolhas alheias em confluência com seus próprios direcionamentos, além de formar cidadãos mais atentos à participações futuras; função coletiva ou integrativa, pois entende o indivíduo em sua comunidade, trabalhando cotidianamente no sentido de melhorar seu entorno social, o que ajuda a tornar as decisões tomadas em conjunto mais facilmente aceitas; função informativa, tanto do ponto de vista da importância das relações cotidianas e trocas comunicacionais horizontais (citizen-to-citizen) e verticais (government-to-citizens); e função de controle, na medida que coloca responsabilidade nas mãos das pessoas para fiscalizar os representantes e, em algum nível, participar das decisões.
Com relação ao segundo ponto, Bucy e Gregson (2001) explicam que, paralelo ao entendimento "clássico" da participação direta e sem intermediários, também é possível identificar ganhos democráticos a partir de mediação por meios digitais. Se acoplarmos a isso um ambiente atual em que cada vez mais a internet faz parte do cotidiano das pessoas, então é compreensível estudar a participação nas redes digitais como um modo natural que os cidadãos encontram para atingir seus objetivos cívicos, seja participando de fóruns locais, seja entrando em contato via e-mail com um deputado.

De fato, ao invés de serem desprezados por uma forma de "pseudo participação", como tradicionalistas (Kerbel, 1999) poderiam caracterizar o uso de novas mídias, os cidadãos se beneficiam da conscientização que a participação midiática fornece proximidade com as elites políticas, faz a política ser continuamente disponível e divertida (acessível), oferece espaço aberto para acesso a uma grande audiência, socializa cidadãos a participarem em assuntos públicos, e permite votantes a cultivarem identidade cívica e conhecer seus próprios gostos [...] (Bucy e Gregson, 2001: $375)^{7}$.

Essas modalidades são entendidas como geradoras de ganhos aos cidadãos a partir da discussão pública de assuntos locais na internet. Bucy e Gregson (2001) explicam que há atividades civis diretas e indiretas que levam a dois tipos de empoderamento do cidadão, simbólico ou material. No campo simbólico, votar, voluntariar-se, corresponder-se e participar de fóruns são consideradas ações de participação ativa. Já seguir discussões políticas mediadas por meios de comunicação e participar de eventos eventualmente são consideradas ações indiretas de participação. No campo material, no entanto, a lógica é de participação ativa via doações e esforços de lobby.

Quando essa dinâmica é colocada mediada pelos meios de comunicação, Bucy e Gregson (2001) destacam que a internet tem influência tanto nos modos de participação ativa/direta, quanto nos modos passivos/indiretos, com especial atenção para o fato de que os atores sociais envolvidos também fazem parte da esfera política. No caso da discussão política de âmbito local, essa dinâmica tende a se reforçar ainda

\footnotetext{
Tradução própria do original em inglês: "Indeed, rather than being slighted by a form of 'pseudo participation', as traditionalists (e.g. Kerbel, 1999) might characterize new media use, the citizen benefits from the awareness that media participation provides proximity to political elites, makes politics continuously available and entertaining (i.e. accessible), offers open-mike access to a wide audience, socializes citizens to participate in public affairs, and allows voters to cultivate a civic identity and know their own minds".
} 
mais, pois, como vimos anteriormente, determinados sites podem servir de fonte de informação local, agregadora de "vizinhos" e ainda promover discussão de assuntos de implicação direta e cotidiana nas pessoas. É importante que se diga que os ganhos democráticos obtidos pelos cidadãos tanto via funções normativas quanto via mediação, na verdade, não brigam entre si. Pelo contrário, eles são pontos que se cruzam em todas as situações, estabelecendo entre si uma relação dialética.

Para fins de sistematização da presente análise, identifica-se quatro ganhos democráticos majoritários na bibliografia de participação: informação, ação educativa, comunidade e monitoramento do poder. Estes são apontados e debatidos pela bibliografia já apresentada e, mesmo que não apareçam exatamente com as estas nomenclaturas, exprimem sistematicamente as mesmas ideias.

A fim de ilustrar e demonstrar exemplos em que os ganhos se projetam, o presente artigo apresenta o resultado de parte de um amplo trabalho de prospecção e avaliação de iniciativas de democracia digital no Brasil, desenvolvido dentro das atividades Centro de Estudos Avançados em Democracia Digital (CEADD), da Universidade Federal da Bahia (UFBA), e das reuniões do Grupo de Pesquisa Comunicação, Internet e Democracia, da mesma instituição. O trabalho, realizado entre 2010 e 2011 e com o envolvimento de 12 pesquisadores, teve como objetivo levantar quais as oportunidades e ferramentas que sites governamentais e não-governamentais oferecem à informação e participação popular, para promoção do governo eletrônico e democracia digital.

No geral, consiste em um estudo exploratório com características de mapeamento a partir da navegação nesses sítios. O intuito é identificar o que há de mais relevante em termos de ferramentas e conteúdos online capazes de contribuir para um bom funcionamento do sistema político. Assim, mecanismos que remetem a itens como informação, transparência, accountability, prestação de contas, controle público, participação etc. são observados e anotados neste relatório. Ao todo, foram analisados 188 sites, distribuídos em 12 categorias: 10 sítios do Poder Executivo Federal (ministérios e órgãos), 27 sítios do Poder Executivo Estadual (governos estaduais), 26 sítios do Poder Executivo Municipal (prefeituras das capitais), 02 sítios do Poder Legislativo Federal (Câmara e Senado), 27 sítios do Poder Legislativo Estadual (assembleias legislativas), 23 sítios do Poder Legislativo Municipal (câmaras municipais das capitais), 04 sítios do Poder Judiciário Federal (tribunais federais), 27 sítios do Poder Judiciário Estadual (tribunais de justiça), 06 sítios de órgãos independentes do campo do Direito (Ministério público etc.), 10 sítios de órgãos independentes no campo da regulação (agências reguladoras), 17 sítios não-governamentais (iniciativas diversas), 09 sítios não-governamentais com ênfase no processo eleitoral.

A partir disso, realizou-se uma nova avaliação de prospecção, dessa vez focada nas iniciativas civis de democracia digital. A orientação mínima requerida exigiu que, na navegação dos sites, fossem acessados todos os links da página inicial, incluindo banners, menus, botões e todo objeto que levasse a alguma outra página de conteúdo ligado à atividade da instituição/ órgão examinado. A segunda fase acompanhou e analisou o conteúdo de cada site, bem como as ferramentas disponíveis. Dessa avaliação, 31 se destacaram por oferecer informações e oportunidades de participação popular para promoção da democracia digital $^{8}$, divididos em sete categorias de acordo com o propósito democrático: monitoramento de contas, obras e políticas; acompanhamento de representantes; informação e educação para a cidadania; participação; expressão de reivindicação civil; deliberação; direitos e acesso à justiça.

Numa fase final mais direcionada, o autor discutiu amplamente a questão do espaço local e da participação online (Carreiro, 2012), refazendo o percurso metodológico de prospecção e análise de sites civis que promovem a participação, mas focados no âmbito local. Um site em especial foi avaliado mais profundamente, o Cidade Democrática ${ }^{9}$, enquanto outros prospectados compuseram o corpo geral para a formulação de uma tipologia de sites dessa natureza: Redes sociais locais, blogs de informação local, comunidades digitais, geolocalização, acompanhamento de representantes, e inputs diretos.

O artigo apresenta a seguir as quatro categorias de ganhos democráticos discutidas a partir da bibliografia apresentada e ilustrada com os exemplos obtidos a partir do caminho metodológico realizado e descrito nos parágrafos anteriores.

\section{Informação}

$\mathrm{Na}$ raiz da democracia participativa, Rousseau (2006) e Mill (2009) veem com especial atenção as relações cotidianas no âmbito local como o espaço primeiro de articulação e participação política. O pensador francês entende a participação dentro de um modelo democrático a partir do compartilhamento de benefícios e malefícios da vida em sociedade,

\footnotetext{
${ }^{8}$ Para mais detalhes a respeito dessa parte do trabalho, verificar Rossetto e Carreiro (2011).

${ }^{9}$ http://www.cidadedemocratica.org.br/
} 
ou seja, indivíduos se comunicam e se relacionam para formarem o bem comum, mesmo que isso traga alguns malefícios, mas é, sobretudo, para alcançar os benefícios que eles se entendem publicamente. A integração social, portanto, ganha ainda mais pujança e se torna fator preponderante para o desenvolvimento democrático sadio. Essa integração é alcançada através da relação dialética entre liberdade individual, participação e controle.

Para que essa engrenagem funcione, é preciso informação para alimentar o repertório político individual dos cidadãos.

É a informação compartilhada sobre o portão do cemitério, ou as resenhas coletadas num café local, ou os debates que se desenvolvem em torno de uma lista de serviços públicos local - o conhecimento de outras pessoas tendo o mesmo conhecimento do local é o que integra a construção do conhecimento local [...] (Gordon, 2008, online) ${ }^{10}$.

Na verdade, a informação que é tida como um ganho democrático para o cidadão se forma em duas concepções. Primeiro, aquela informação obtida de forma individual, na busca por um conhecimento que alimente a coleção de informação sobre determinado assunto e que vai ser, mais cedo ou mais tarde, importante para uma discussão política ou uma discussão que possa ter implicação política. Segundo, e mais importante, aquele tipo de informação que, como afirmou Gordon, é compartilhada e foi construída socialmente a partir de fluxos informativos que costuram as relações sociais. Na concepção de Bucy e Gregson (2001), adquirir informação é um tipo de ganho de caráter psicológico e cognitivo, isto é, não resulta em um resultado efetivo e direto que pode ser quantificado ou mensurado. Mas, sim, atua no sentido de dar base para outros tipos de ganhos mais ativos e com implicação material mais "palpável”, conforme veremos nos tópicos seguintes.

Em São Paulo, cidadãos podem utilizar o Urbanias $^{11}$ para denunciar (através de fotos, vídeos e descrição da situação por escrito) os pontos da cidade que apresentam problemas em diversos setores que concernem à qualidade de vida na cidade e, por conseqüência, afetam o dia-a-dia dos moradores, como problemas relacionados ao trânsito, ônibus e metros, ruas e calçadas, lixo e poluição, acessibilidade, dentre outros assuntos. Nesse caso,

\footnotetext{
${ }^{10}$ Tradução própria do original em inglês: "It is the shared information about the cemetery gate, or the collected reviews of a local café, or the debates that take place on a local listserv - the knowledge of other people having the same knowledge of location is integral to the construct of local knowledge".

${ }^{11}$ http://www.urbanias.com.br
}

que se encaixa na categoria Geolocalização, há a formação de um composto informativo sobre diversas questões paulistas, apresentando, ainda, um quadro geral formador de uma agenda pública de problemas.

No exemplo citado, o cidadão contribui para informação geral sobre São Paulo, ao apontar onde exatamente está o problema e qual é essa questão que afeta a cidade, para uma informação direcionada sobre segurança e consegue receber um feedback de sua reclamação. A partir desse processo, o indivíduo ainda compartilha a questão com os amigos, por meio do Facebook, e amplia o alcance do conteúdo, contribuindo, mais uma vez, para o composto informativo geral da cidade. Além disso, ele ainda entra em contato, mesmo que indiretamente, com a empresa responsável pela solução do seu problema, mais um tipo de informação que irá compor o repertório local do cidadão para futuras participações.

A disponibilidade de informação pertinente e a facilidade com a qual floresce pode fazer uma significante diferença na qualidade de vida das vizinhanças. A partilha de informação é um ingrediente essencial, mas curiosamente negligenciado em capital social local. Onde a informação e a comunicação são sufocados, confiança e cooperação são menos propensos a prosperar. Onde eles florescem, residentes podem sentir mais empoderados e prontos para engajar em processos de co-produção [...] (Flouch e Harris, 2010: 2$)^{12}$.

No caso brasileiro, um estudo ${ }^{13}$ mostra que os níveis de participação e engajamento dos cidadãos, em qualquer nível (local, regional ou nacional), são baixos: $12 \%$ e $18 \%$, respectivamente, do total da população brasileira. Outra estatística mostra que apenas $4 \%$ dos brasileiros se sentem muito informados sobre política governamental e $49 \%$ se sente pouco informado sobre a mesma questão. Esses dois conjuntos de índices podem mostrar que há uma relação direta entre participar/engajar em questão pública e se sentir informado sobre política, ainda que esta esteja ligada à política de ordem governamental. Numa comparação com o caso inglês analisado por

\footnotetext{
${ }^{12}$ Tradução própria do original em inglês: "The availability of pertinent information and the ease with which it flows can make a significant difference to the quality of life in neighbourhoods. The sharing of information is an essential but curiously overlooked ingredient in local social capital. Where information and communication are stifled, trust and co-operation are less likely to thrive. Where they flourish, residents can be expected to feel more empowered and ready to engage in coproduction".

${ }^{13}$ Pesquisa sobre o Uso das Tecnologias da Informação e da Comunicação no Brasil - TIC Governo Eletrônico 2010, do Núcleo de Informação e Coordenação do Ponto BR. Disponível em: http://www. cetic.br/tic/egov/2010/index.htm
} 
Flouch e Harris (2010), vemos que o uso contínuo de sites que pretendem fornecer participação dá subsídios para que cidadãos se sintam informados sobre suas cidades, sendo que $92 \%$ dos pesquisados afirmam entender que informação local útil é compartilhada eficientemente, enquanto que $74 \%$ confiam no conteúdo que é divulgado e produzido no âmbito de sites locais.

\section{Ação educativa}

Tanto do ponto de vista da democracia participativa quanto da perspectiva deliberativa, é possível entender a importância que a conversação cotidiana tem para a formação e participação política dos cidadãos. As relações cotidianas têm papel fundamental para a participação política dos cidadãos, seja no âmbito da informação, da formação de um sentido comunitário próprio ou no monitoramento da classe política local. Esses elementos juntos têm o poder de formar um composto educativo forte, perpassando diversos momentos e/ou aspectos da vida social da cada indivíduo, contribuindo para que as pessoas formem suas concepções políticas individuais, ajudando para que essas questões sejam mantidas na comunidade e "digeridas" de forma a garantir continuidade desse processo, e montando o repertório pessoal para participação mais efetiva em questões políticas locais.

Vitale (2006) lembra que a formação de um indivíduo consciente politicamente é imprescindível para a consolidação de uma democracia participativa, o que implica na formação contínua das pessoas, conforme apontado acima. Essas questões envolvem, como pode ser visto na categoria Comunidade, um forte senso comunitário "[...] porque a própria identidade e os interesses dos indivíduos são marcados pela inserção nessa comunidade [...]" (Maia, 2011: 13). Claro que é importante ressaltar que isso não implica numa perspectiva neo-tocquevilleana (como, aliás, a própria autora prefere enquadrar a questão), afinal, estamos tratando de um contexto social marcado por interações que podem ser realizadas sem barreiras físicas (redes digitais). Isso quer dizer que, mesmo pensando o bem de uma localidade específica, pessoas podem fazer isso utilizando informações e outras questões ligadas a outras localidades como forma de adquirir subsídios para tal.

Em longo prazo, esse aspecto educativo esbarraria num anteparo robusto: a vida cotidiana traz consigo

[...] uma constante tensão entre a afirmação instrumental de interesses (no limite, dos interesses individuais) e a constituição de solidariedades e de identidade coletiva, em diferentes graus [...] (Maia, 2011: 14).
De fato, Rousseau (2006), já no século XVIII, previa isso, mas entendia que a própria ação educativa gerada pelos processos contínuos de participação iria sanar tal problema, uma vez que os cidadãos aprenderiam a contrabalancear interesses pessoais com os coletivos - ou, em maior instância, igualar os dois interesses.

Outra forma de compreender isso é por meio da noção de que o cidadão só vai se esforçar para participar se entender que há benefício para ele, e se houver, se o benefício que ele recebe vale à pena.

Imagino, contudo, que as pessoas, mesmo limitadas e visitadas por valores e interesses que condicionam e possibilitam sua decisão de participar, sejam capazes de identificar e determinar razões para a sua participação e que tais razões (que não precisam ser realmente racionais) funcionam como motivações suficientes para a sua ação em geral [...] (Gomes, 2011: 31).

Como vimos anteriormente nesse capítulo, a internet tem se misturado cada vez mais às práticas cotidianas, o que nos faz estabelecer a mínima conexão entre as duas situações. Quer dizer, se a política e a participação podem e devem ser realizadas no âmbito local e se misturam às práticas cotidianas, também é possível entender como a internet se "intromete" nesse meio, servindo de base para praticamente qualquer ação social, como namorar, relacionar-se profissionalmente, fazer investimentos, conversar e, claro, estabelecer conexões políticas e de participação.

Na Inglaterra, Flouch e Harris (2010) mostram que o uso de sites de informação e participação local está ligado a altos níveis de benefícios sociais e psicológicos percebidos. Ou seja, as pessoas tendem a voltar àqueles sites locais que são entendidos como ativadores de tais ganhos democráticos. Essa continuidade também é concebida no âmbito das discussões empreendidas por meio das ferramentas apresentadas, pois os indivíduos se sentem cada vez mais compelidos a participar. Essas questões evocam, inevitavelmente, uma breve consideração sobre capital social ${ }^{14}$, pois estamos tratando de situações que geram sentido de eficácia coletiva e obtenção de bens sociais e simbólicos a partir da participação.

A realização de Orçamentos Participativos (OP) em todo mundo, mais especialmente no Brasil, vem de uma tradição de esquerda. Independente disso, o fato é que em diversas cidades brasileiras esse modelo vem

\footnotetext{
${ }^{14}$ Adotamos a noção geral de capital social de Pierre Bourdieu, descrita assim por Heloisa Matos (2009): “[...] conjunto de recursos atuais e potenciais que estão ligados à posse de uma rede durável de relações mais ou menos institucionalizadas de interconhecimento e inter-reconhecimento $[\ldots]$ ".
} 
se consolidando como forma de colocar nas mãos do povo certa responsabilidade acerca dos investimentos do Estado nas mais diversas áreas. Em Porto Alegre, o OP já é realizado desde 1989 com relativo sucesso, adquirindo cada vez mais participantes e se alinhando às novas tecnologias, assim como o OP de Belo Horizonte. No caso mineiro, Sampaio (2010) mostrou como a prefeitura da cidade conseguiu utilizar ferramentas da internet para dispor de novos inputs participativos e discursivos, transformando esses fóruns em arenas deliberativas.

De modo geral, dentre outras conclusões que podem ser obtidas (Sampaio, 2010), é possível identificar que a constante participação nesse tipo de atividade aciona processos cognitivos e contínuos no cidadão. Aumenta o capital social em diversos aspectos, na medida em que coloca ao indivíduo poder para opinar e interferir em questões que implicarão diretamente em suas vidas. No plano comunitário, forma um processo educativo que cresce a cada ano, angariando mais participante ${ }^{15}$ e empoderando aqueles que já participaram, para que em futuras consultas também possam aproveitar melhor tal oportunidade.

Além disso, houve preocupação em identificar pontos da cidade com pouco acesso à internet e levar, através de unidades móveis, acesso a computadores para que ampliasse o alcance do OP a outras regiões. Some-se a isso a oferta de 152 centros de inclusão digital espalhados por Belo Horizonte e região metropolitana, espaços dedicados a oficinas de inclusão digital e participação no orçamento digital. Alia-se, desse modo, uma prática participativa direta em questões sociais locais e a formação continuada de cidadãos para futuros processos digitais ${ }^{16}$.

\section{Comunidade}

Pateman (1992) explica que o espaço local é o primeiro onde o cidadão "aprende" os ideais de democracia, como respeito mútuo, noção de ação compartilhada, equilíbrio entre necessidades pessoais e coletivas, entende como deve ser feita a participação juntamente com outros residentes etc.

\footnotetext{
${ }^{15}$ De 15 mil pessoas em 1994 para 44 mil em 2009/2010. Números obtidos em revista comemorativa dos 15 anos do OP de $\mathrm{BH}$ Disponível em: http://www.pbh.gov.br/comunicacao/pdfs/ publicacoesop/revista_15anos_portugues.pdf

${ }^{16}$ Sobre os orçamentos participativos em geral, vários autores direcionaram críticas a fatores como a representatividade daqueles que participam, questões sobre recursos e temas de discussão, presença de grupos de interesses em detrimento de cidadãos, dentre outros. São questionamentos que põem em dúvida a legitimação da deliberação nesses meios, evidenciando, por exemplo, o fato de que os cidadãos concernidos não são democraticamente eleitos (Nylen, 2003; Cortes, 2005; Marques, 2008).
}

Mas como a participação política pode gerar o sentido comunitário como ganho democrático para o cidadão? Para responder essa questão, recorremos à Galston (2002) e suas características estruturais de uma comunidade. Primeiro, uma comunidade possui membros limitados, mas não no sentido de exclusão arbitrária, e sim pelo viés do se "sentir pertencer" àquele local, seja por questão familiar, tradicional ou história, seja por escolha. O autor explica que há custos de entrada e saída da comunidade e esses dois fatores estão ligados intimamente ao "poder de fala" dentro do espaço local. Ora, se a participação pressupõe que o cidadão tome parte de determinada situação política que lhe interessa, então é avaliando os custos sociais para tal que o indivíduo irá participar e, consequentemente, beneficiar-se do sentido de pertencimento àquele local o qual ele ajudou a melhorar tal situação política.

Diferentemente do 'self' livre do liberalismo, o 'self' comunitário é entendido como sendo constituído nas relações estruturadas pelo papel social e pela subjetividade compartilhada. A comunidade vem antes e permite liberdade individual, expressão e democracia. O diálogo democrático serve à vida comum em grupo, mais do que a interesses individuais privados. Permite que membros da comunidade descubram suas identidades compartilhadas e propostas $[\ldots]$ (Dahlberg, 2001: 163) ${ }^{17}$.

É o caso de fóruns na internet, redes sociais online, listas de discussão, sites de informação local etc. Eles também formam um composto de comunicação localizada, enraizando-se cada vez mais no cotidiano das pessoas e abrindo novos inputs de participação local. As ligações via redes digitais seguem propósitos distintos, como, por exemplo, as comunidades de escolha (Frey, 2003), construídas a partir de interesses específicos em comum. No caso aqui discutido, no entanto, trata-se de uma comunidade de escolha no sentido de interesse compartilhado, mas esse interesse é condicionado ao espaço físico, aos assuntos concernentes a esse espaço. Condicionado, porém, não limitado, pois embora possa se discutir diversos aspectos acerca de tais comunidades, há um caminho bem pavimentado em direção ao complemento digital da concepção social compartilhada do local.

\footnotetext{
${ }^{17}$ Tradução própria do original em inglês: "Unlike the unencumbered self of liberalism, the communitarian self is understood to be constituted within relationships structured by social roles and shared subjectivity. The community comes before and enables individua freedom, expression and democracy. Democratic dialogue serves the common life of the group, rather than the interests of a private individual. It enables members of a community to discover their shared identity and purpose".
} 
Na mesma linha está o City Bahnhof Ulm ${ }^{18}$, de Ulm, na Alemanha, site que se dedicou a discutir uma questão específica: planejamento urbano da cidade. Esse propósito foi aos poucos se ampliando e hoje é possível acompanhar diversas outras discussões pontuais empreendidas pelos cidadãos. No Brasil, também há exemplos semelhantes, como o site Meu Rio e o Movimento Boa Praça ${ }^{19}$. O primeiro caso se refere à união de forças em torno da melhoria de questões pontuais do Rio de Janeiro, como a realização da Copa do Mundo na cidade e seus impactos sociais. Além disso, o site utiliza as redes sociais online para angariar mais pessoas em torno de outros projetos, como forma de pressionar a classe política para questões mais gerais, como fim da violência e da corrupção.

Os cidadãos que participam via Meu Rio só o fazem porque vêem no site a promoção de causas que eles também compartilham, causas essas que, de uma forma ou de outra, integram a agenda pública de problemas locais. Ao compartilhar no facebook a petição sobre a lei da Ficha Limpa estatal, o indivíduo está mostrando aos seus amigos que se importa com a cidade, com o bem estar da comunidade local. Assim, outras pessoas são "intimadas" a fazerem um mesmo, montando uma rede de cooperação em torno de interesses similares que, em última instância, é o bem comum da cidade do Rio de Janeiro.

No site do Movimento Boa Praça, desenvolvido na plataforma Ning, os cidadãos de Belo Horizonte se juntam para discutir questões diversas, mas todos estão imbuídos do sentimento de preservação do local físico compartilhado por todos, a praça. O texto de apresentação do Movimento diz que o objetivo é "mobilizar as pessoas para revitalizar e ocupar as praças, devolvendo a elas seu sentido inicial: de lugar de encontro, diversão, debate e inclusão". Ao participarem nessas iniciativas e atividades comunitárias, os indivíduos desenvolvem alto senso de eficácia coletiva e,a ainda, conseguem pressionar políticos para realização de ações semelhantes em outras regiões da cidade. De fato, as atividades comunitárias são realizadas no espaço físico, mas o senso do local é compartilhado no site, que também é utilizado para marcar reuniões, debater outras questões e agregar mais pessoas para o Movimento.

Mesmo que geograficamente longe, essas pessoas compartilham interesses, gostos, sentimentos e planos relacionados à cidade. São essas questões que tornam os cidadãos próximos e que são formados a partir

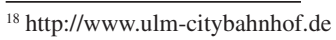

${ }^{19}$ Respectivamente: http://meurio.org.br/ e http://boapraca.ning.com/
}

da participação deles em tais comunidades, sites, ferramentas e iniciativas digitais diversas. É salutar lembrar, no entanto, que essas relações não excluem as discussões face a face ou as participações em processos locais de cunho físico, em que é necessária a presença individual.

No estudo de Hampton (2010), ele encontra evidências de que, num cenário de desvantagem social e com problemas sociais marcantes, as pessoas tendem a procurar soluções para essas questões. Envolvem-se em discussões locais, engajam-se em causas e, no caso do contexto mais recente, também utilizam a internet para tal. O resultado dessa participação é a formação mais coesa do sentimento de eficácia coletiva. Pelo mesmo caminho aponta Lev-On (2010) em trabalho sobre o Katif.net, que se formou com um propósito específico: reunir a população de Gush Katif, comunidade judaica da Faixa de Gaza, que foi expulsa de seu território em 2005. Como o artigo demonstra, o Katif.net se estabeleceu como "local" de encontro de famílias desagregadas e pessoas em busca de discussão de problemas e questões relacionadas à localidade perdida.

\section{Monitoramento do poder}

A noção básica de política, apresentada anteriormente por Bobbio (1998), vincula sua prática à realidade urbana, civil e pública, isto é, mostrando que sua origem, embora calcada numa época antiga sem horizonte de extensão territorial tão vasta como hoje, já previa o entorno social do cidadão como espaço primeiro de articulação política. Ao trocar informações, compartilhar idéias e relacionar-se com seus vizinhos, o cidadão se faz e se reflete na relação diária. Mediado ou não por meios de comunicação, esse processo resulta em aspectos culturais específicos de cada local, que também podem ser acionados de diferentes locais, como em iniciativas de democracia digital.

Tanto para Felizes (2000) quanto para Silva, M. (2009), a complexa relação de forças nos ambientes urbanos atuais denota a necessidade da sociedade civil também atuar de forma combativa, pois é dessa forma que se evitaria a perpetuação no poder de determinados grupos específicos. Mas esses poderes se estruturam de duas formas: de um lado, na esfera institucional, burocrática e organizada, e, do outro, no sentido de

[...] um poder difuso mais próximo do quotidiano social, das relações que envolvem estratégias mais ou menos conscientes de apropriação e utilização desse poder [...] (Silva, M., 2009: 2). 
É justamente nesse ponto onde os indivíduos se beneficiam e a noção de monitoramento do poder pode ser entendida mais claramente como um ganho democrático. Em sua relação cotidiana, ao conversar com amigos, discutir na porta da padaria e se envolver mais diretamente em processos participativos mais organizados, o indivíduo se sente parte do processo de construção da sua localidade, isto é, torna-se mais um dos que pensam a comunidade e permanece monitorando o andamento da mesma, seja do ponto de vista institucional (por intermédio de inputs diretos), seja nas relações do dia a dia. É importante que se ressalte o peso do equilíbrio entre forças de poder governamental e do poder civil, independente se é organizada ou do ponto de vista individual.

Imaginar que as instituições podem apresentar um bom desempenho sem algum substrato de cultura cívica é algo logicamente pouco adequado. Catedrais certamente requerem fiéis. Assim, as duas dimensões devem ser vistas como partes de um todo e, nesse sentido, o esforço analítico deve atentar para as características e processos que se desenvolvem nas esferas da sociedade civil e das instituições [...] (Rocha, 2011: 174).

Certamente, nesse ponto do trabalho já é possível trazer a internet para o debate de forma mais natural, afinal, práticas políticas civis nas redes digitais já se tornaram comuns e fruto de inúmeros estudos, como vimos anteriormente no primeiro capítulo. Mesmo em estudos sobre internet e política, a questão da eficácia política é tratada como um aspecto importante a ser considerado como ganho para o cidadão (Bucy e Gregson, 2001; Mccluskey et al., 2004; Flouch e Harris, 2010). Esses estudos retomam a ideia de eficácia política de autores mais antigos, como Pateman (1992) - ou, numa questão prática, aplicam tal noção às atuais apropriações participativas da internet. Basicamente, cidadãos são mais propensos a participar porque entendem que seu envolvimento pode influenciar na decisão política final. Isso significa dizer que esse senso de eficácia política só é alcançado porque, em algum momento anterior, já houve participação. De outro modo, sem participar, seria ilógico pensar em como um indivíduo perceberia que sua participação teria efeito prático.

Em estudo sobre sites locais de participação, Flouch e Harris (2010) identificaram que mais da metade (59\%) dos usuários dessas iniciativas se sentiam hábeis a influenciar no processo decisório de sua área. Como conclusão, os pesquisadores explicam que pode-se dizer que o uso desses sites proporciona mais contato entre cidadãos e agências do governo ou até mesmo políticos, além de, em alguns casos, contribuir para a formação de processos colaborativos na feitura de projetos ou na decisão de políticas públicas específicas. Em outro questionamento semelhante, $68 \%$ dos usuários se sentiram mais hábeis em influenciar a decisão política após terem participado via site.

Em São Paulo, o projeto Adote um Vereador recruta cidadãos para que adotem vereadores da cidade e passem a fiscalizar mais de perto suas ações. Para tanto, cada "adotado" tem um blog, em que o cidadão escolhido passa a preencher com informações e conteúdo em geral a respeito do andamento das atividades do legislador. O cidadão Alecir Macedo é o responsável pelo blog Cuidando da Cidadania, dedicado a acompanhas as ações de Netinho de Paula (PCdoB). Embora careça de atualizações mais constantes, o site integra uma rede de outros $10 \mathrm{blogs}$ com o mesmo propósito, cada um investigando mais à fundo um vereador diferente.

Esse tipo de ação passa a fazer parte da vida cotidiana do cidadão, que congrega a suas atividades diárias mais uma, a de monitorar e municiar de informação um blog somente para ser um sentinela do vereador. Além disso, os integrantes do Adote um Vereador realizam encontros presenciais, onde trocam experiências e até acompanham sessões da Câmara. $\mathrm{Na}$ mesma linha está o Adote um Distrital ${ }^{20}$, iniciativa com enfoque nos parlamentares do Distrito Federal. Lá, a diferença é que os posts sobre cada "adotado" é disposto na mesma timeline, mas a proposta é a mesma, tanto do ponto de vista da informação política direcionada, quanto da congregação para encontros presenciais.

Diante desse quadro, diversas outras atividades online podem ser encaradas como participativas que geram esse senso de monitoramento do poder e eficácia política, como voluntariado, escrever para representantes, engajamento avulso e participação em fóruns. Essas são ações diretas, do ponto de vista da participação em si, e simbólicas, em relação ao empowerment (ganho) para o cidadão (Bucy e Gregson, 2001). Numa escala de nível de influência, o monitoramento do poder como ganho estaria num patamar próximo ao poder institucional, pois há certa influência sobre ele, mas, também, não tão perto a ponto de se tornar influência direta na arena de dos policymakers. No caso mais específico da participação na internet, essa é uma questão até natural dado seu caráter cada vez mais pervasivo na vida das pessoas e, por isso, torna-se uma ferramenta poderosa para beneficiar os cidadãos no que diz respeito à manter a percepção de responsividade do sistema político.

\footnotetext{
${ }^{20}$ Posts agregados sobre o distrital Chico Vigilante: http:// adoteumdistrital.com.br/category/chico-vigilante/.
} 
Mesmo no âmbito local, em que teoricamente um contato face a face com políticos seria mais fácil, a internet pode ajudar o cidadão a ultrapassar uma possível barreira. Com a popularização de redes sociais online, por exemplo, diversos políticos passaram a adotá-las como ferramenta de comunicação e cidadãos, agregados muitas vezes em campanhas espontâneas, formam um composto suficientemente robusto de pressão. Num levantamento realizado entre os vereadores de São Paulo ${ }^{21}$, $82 \%$ tem perfil no Twitter e, destes, $42 \%$ respondem a perguntas feitas pela ferramenta. Além disso, $64 \%$ dos vereadores possuem fanpages no Facebook e 55\% usam o Youtube como ferramenta de comunicação.

Exemplo disso são os diversos políticos brasileiros com perfis no Twitter. A ferramenta de comunicação digital instantânea dá ao parlamentar a possibilidade de mostrar suas atividades, cobrar outros políticos e, principalmente, manter contato com seus eleitores. Nesse caso, fica claro o ganho para o cidadão da comunicação via Twitter, afinal, mesmo trocando uma ferramenta (e-mail) pela outra (microblog), o indivíduo realiza uma atividade de participação que propicia a ele um contínuo acompanhamento de seu representante, além de se tornar um composto razoavelmente forte de futuras interações para outros propósitos.

\section{Conclusão}

$\mathrm{O}$ trabalho realizado até aqui permitiu discutir diversas questões sobre a participação política online de âmbito local, servindo como base para entender, principalmente, como as apropriações civis da internet podem gerar novos inputs participativos e serem modos de empoderamento dos cidadãos envolvidos.

Esses ganhos são importantes pelo viés individual e coletivo. Quanto ao primeiro ponto, os cidadãos beneficiados conseguem se aparelhar informativamente e politicamente, pois, de um lado eles conseguem obter informações locais importantes para o processo participativo que está em curso, e de outro, eles se tornam cada vez mais aptos a participarem e se envolver nas questões da sua localidade. No plano coletivo, os ganhos ajudam na manutenção do próprio sistema, isto é, os indivíduos beneficiados pela participação nas quatro dimensões analisadas (informação, ação educativa, comunidade e monitoramento do poder) estão empoderados a ponto de se manter participando pelo bem comum e da sua

\footnotetext{
${ }^{21}$ Pesquisa disponível em: http://www.medialogue.com.br/wp-content/ uploads/downloads/2011/10/politico-20-vereadores2-sp1.pdf. Acesso em: 8 nov. 2011.
}

própria comunidade. Além disso, entendemos que a internet pode ajudar para que a comunidade veja a participação como um processo contínuo, uma vez que as redes digitais habitam o cotidiano das pessoas e perpassam (ou são base para) as trocas informativas diárias.

A participação política local online evidencia, portanto, que pode ser geradora de ganhos democráticos empoderadores, que envolvam o cidadão na esfera individual, do ponto de vista do aparelhamento pessoal para práticas sociais e políticas para o bem local, e na esfera coletiva, como na percepção de senso de comunidade. A limitação está em seu próprio processo, pois há uma clara necessidade de envolver mais cidadãos durante a participação. Em estudo anterior (Carreiro, 2012) isso fica claro: mesmo que cidadãos reconheçam a potencialidade de determinada ferramenta, só foi possível identificar resultados realmente efetivos em ambientes sociais específicos que contam com articulação concreta de cidadãos, entidades e agentes políticos preocupados com a cidade e participando ativamente presencialmente e no meio online.

Ainda assim, o estudo demonstra que, do mesmo jeito que autores como Pateman (1992) evidenciaram, a participação política local é um modo eficiente de gerar benefícios para seus cidadãos, pois é o espaço primeiro de articulação social de cada indivíduo. E a internet, como parte importante da sociedade atual, é capaz de se tornar meio e oportunidade para tal.

\section{Referências}

Barber, Benjamin. 1984. Strong Democracy: participatory politics for a new age. Londres e Los Angeles: University of California Press.

Berger, Guy. 2009. How The Internet Impacts On International News: Exploring Paradoxes of the Most Global Medium in a Time of 'Hyperlocalism'. The International Communication Gazette, 1748-0485, 71(5): 355-371.

Bobbio, Norberto. 1998. Dicionário de Política. Brasília: Editora Universidade de Brasília.

Bucy, Erik e Gregson, Kimberly. 2001. Media participation: A legitimizing mechanism of mass democracy. New Media \& Society, 3(3): 357-380.

Carreiro, Rodrigo. 2012. Participação Política Local Através da Internet e os Ganhos Democráticos para o Cidadão Online. Dissertação de Mestrado, Universidade Federal da Bahia.

Chadwick, Andrew. 2006. Internet politics: States, citizens, and new communication technologies. Nova York, Oxford: Oxford University Press. 
Coleman, Stephen e Blumler, Jay. 2009. The Internet and Democratic Citizenship: theory, practice and Policy. Cambridge: Cambridge University Press.

Coleman, Stephen e Norris, Donald. 2005. A new agenda for e-democracy. Oxford, Forum Discussion, paper no. 4.

Coleman, Stephen. 2009. Making parliamentary democracy visible: speaking to, with, and for thepublic in the age of interactive technology. In A. Chadwick; P. N. Howard (orgs.), Routledge Handbook of Internet Politics. Taylor \& Francis e-Library.

Cortes, Soraya. 2005. Fóruns participativos e governança: uma sistematização das contribuições da literatura. In C. Lubambo; D. B. Coelho; M. A. Melo (orgs.), Desenho Institucional e participação política: experiências no Brasil contemporâneo. Petrópolis, Vozes.

Dahlberg, Lincoln. 2001. Democracy via cyberespace: mapping the rhetorics of three prominent camps. New Media \& Society, 3(2): 157-177. http://dx.doi. org/10.1177/14614440122226038

Dowbor, Ladislau. 1994. O Que É Poder Local. Brasiliense, Coleção Primeiros Passos.

Dowbor, Ladislau. 1998. A Reprodução Social: proposta para uma gestão descentralizada. Vozes. Disponível em: <http://dowbor.org/artigos/repro-98.doc>. Acesso em: 14 jun. 2011.

Egler, Claudio. 2010. Apontamentos sobre rede urbana e políticas públicas no Brasil. In $\mathrm{R}$. Matos; W. Soares (orgs.), Desigualdades, redes e espacialidades emergentes no Brasil. Rio de Janeiro: Garamond, 352 p.

Felizes, Joel. 2000. Três abordagens do poder local enquanto formas diferenciadas de construção das identidades - uma breve exploração. Universidade de Coimbra, Portugal, Atas do IV Congresso Português de Sociologia. APS Publicações.

Flouch, Hugh e Harris, Kevin. 2010.Online Neighbourhood Networks Study. Disponível em: $<$ http://networkedneighbourhoods.com/?page $\mathrm{id}=409>$. Acesso em: 15 set. 2011.

Frey, Klaus. 2003. Desenvolvimento Sustentável Local na Sociedade em Rede: o potencial das novas tecnologias de informação e comunicação. Revista Sociologia e Política, 21: 165-185. http://dx.doi. org/10.1590/S0104-44782003000200011

Galston, William. 2002.The Impact $f$ the Internet on Civic Life: an early assessment. In E. C. Kamarck; Joseph S. Nye Junior (orgs.), Governance.com: Democracy in the Information Age. Washington: Brookings Institution Press, p. 140-57.

Gomes, Wilson. 2005. A democracia digital e o problema da participação civil na decisão política. Revista Fronteiras - estudos midiáticos. VII(3), Unisinos.
Gomes, Wilson. 2008. Internet e Participação Política. In: W. Gomes; R. C. M. Maia, Comunicação e Democracia: problemas \& perspectivas. São Paulo: Paulus.

Gomes, Wilson. 2011. Participação política online: questões e hipóteses de trabalho. In W. Gomes; R. C. M. Maia; F. P. J. A. Marques. Participação política e internet. Porto Alegre: Sulina.

Gordon, Eric. 2008.Towards a theory of Network Locality. First Monday, 13(10).

Hampton, Keith. 2010. Internet Use and the Concentration of Disadvantage: Glocalization and the Urban Underclass. American Behavioral Scientist, 53(8): 1111-1132. http://dx.doi. org/10.1177/0002764209356244

Held, David. 2006. Models of Democracy. 3rd ed. Polity Press.

Knudsen, Anne-Marie Sanvig. 2007. The Right To The City: Spaces Of Insurgent Citizenship Among Pavement Dwellers In Mumbai, India. UCL Development Planning Unit, DPU, n 132.

Lefebvre, Henri. 2001. O Direito à Cidade. 5. ed. São Paulo: Centauro.

Lev-On, Azi. 2010. Engaging the Disengaged: Collective Action, Media Uses, and Sense of (Virtual) Community by Evacuees From Gush Katif. American Behavioral Scientist, 53(8): 1208-1227. http://dx.doi org/10.1177/0002764209356251

Maia, Rousiley. 2011. Sob a perspectiva da esfera civil: participação política e internet. In W. Gomes; R. C. M. Maia; F. P. J. A. Marques, Participação política e internet. Porto Alegre: Sulina.

Marques, Francisco Paulo Jamil. 2008. Participação política e internet: meios e oportunidades digitais de participação civil na democracia contemporânea, com um estudo do caso do estado brasileiro. Tese de doutorado, Universidade Federal da Bahia.

Matos, Heloiza. 2009. Capital Social e Comunicação interfaces e articulações. São Paulo: Ed. Summus.

McCluskey, Michael; Deshpande, Sameer; Shah, Dhavan e Mcleod, Douglas. 2004. The Efficacy gap and political participation: when political influence fails to meet expectations. International Journal of Public Opinion Research, 6(4): 437-455. http://dx.doi. org/10.1093/ijpor/edh038

Mill, John Stuart. 2009. Considerations on Representative Government. The Floating Press.

Nylen, William. 2003. Participatory Democracy versus Elitist Democracy: Lessons from Brazil. New York: Palgrave MacMillan. http://dx.doi. org/10.1057/9781403980304

Pateman, Carole. 1992. Participação e Teoria Democrática. Rio de Janeiro: Paz e Terra.

Rocha, Carlos Vasconcelos. 2011. Gestão Pública Municipal e Participação Democrática No Brasil. Revista de Sociologia e Política, 19(38): 171-185. http:// dx.doi.org/10.1590/S0104-44782011000100011 
Rossetto, Graça Penha Nascimento e Carreiro, Rodrigo. 2011. Democracia digital e sociedade civil: uma perspectiva do estado atual no Brasil. Rio de Janeiro, Anais do IV Encontro da Compolítica.

Rousseau, Jean-Jacques. 2006. O Contrato Social. São Paulo: Escala Fundamental.

Saebo, Øystein; Rose, Jeremy e Molka-Danielsen, Judith. 2010. eParticipation: Designing and Managing Political Discussion Forums. Social Science Computer Review, 28(4): 403-426. http://dx.doi. org/10.1177/0894439309341626

Sampaio, Rafael. 2010. Participação e Deliberação na Internet: um estudo de caso do Orçamento Participativo Digital de Belo Horizonte. Dissertação de Mestrado, Universidade Federal de Minas Gerais.

Santos, Milton. 2008. Técnica, Espaço, Tempo. 5. ed. São Paulo: EdUSP.

Schlosberg, David e Dryzek, John. 2002. Digital Democracy: Authentic or virtual? Organization \& Environment, 15(3): 332-335. http://dx.doi. org/10.1177/1086026602153011
Silva, Marcia da. 2009. Estado e Poder Local: ensaio teórico sobre estudos no Brasil. Revista Bibliográfica de Geografía y Ciencias Sociales, XIV(841).

Silva, Sivaldo Pereira. 2009. Estado, democracia e internet: requisitos democráticos e dimensões analíticas para a interface digital do Estado. Tese de Doutorado, Universidade Federal da Bahia.

Teixeira, Elenaldo. 2002. O local e o global: limites $e$ desafios da participação cidadã. 3. ed. São Paulo: Cortez.

Vitale, Denise. 2006. Democracia direta e poder local: a experiência brasileira do Orçamento Participativo. In V. S. R. P. Coelho e M. Nobre (orgs.). Participação e deliberação: Teoria democrática e experiências institucionais no Brasil contemporâneo. 1a ed. São Paulo: Editora 34 e DRC, p. 239-254.

Ward, Stephen e Gibson, Rachel. 2009. European political organizations and the internet: mobilization, participation, and change. In A. Chadwick e P. Howard (orgs.). Routledge Handbook of Internet Politics.Taylor \& Francis e-Library. 